\title{
A Virtude da Integridade Para uma Teoria da Legislação
}

\author{
Elias Kallás Filho \\ Pós-doutor da Fundação São Francisco de \\ Assis. Doutor pela Universidade de São Paulo. \\ Professor do Programa de Pós-Graduação \\ Stricto Sensu da Faculdade de Direito do Sul \\ de Minas. Advogado.ekf@fdsm.edu.br
}

\section{Meliza Marinelli Franco Carvalho}

Mestranda em Constitucionalismo e Democracia pela Faculdade de Direito do Sul de Minas. Bolsista Fapemig. melizamarinellifranco@hotmail.com

\section{Resumo}

Por meio do estabelecimento de uma relação entre as exigências normativas do princípio da integridade e a prática legislativa brasileira, esta investigação oportuniza a abertura de uma reflexão que ultrapassa a questão da coerência e consistência na área da decisão jurídica, para alcançar também uma possível normatividade no campo da produção legislativa. Nessa perspectiva exploratória, esta reflexão permite uma discussão sobre o próprio equilíbrio ou mediação da tensão entre constitucionalismo e democracia no âmbito da produção legislativa do Direito. Para tanto, a pesquisa fará uma abordagem analítica, utilizando-se das reflexões teóricas da hermenêutica política de Ronald Dworkin, especialmente em suas obras que tratam da integridade do Direito. Conclui-se que a integridade deve ser vista pelo legislador como uma virtude do Direito a ser respeitada em todas as etapas do processo legislativo, pois quando a decisão de criar novas normas e novos direitos for justificada em princípios de moralidade política, a legislação como um todo ganhará em legitimidade e eficácia.

Palavras-chave: Integridade. Processo legislativo. Moralidade política. Legitimidade. 


\title{
The Virtue of Integrity for a Theory of Legislation
}

\begin{abstract}
By establishing a relation between the normative requirements of the principle of integrity and Brazil's legislative practice, this research provides an opportunity to open a discussion that goes beyond the issue of coherence and consistency in the field of legal decision, to also reach a possible normativity in the field legislative production. In this exploratory perspective, this reflection allows a discussion of the balance or mediation of the tension between constitutionalism and democracy within the legislative process of law. To do so, the research will take an analytical approach, using the theoretical reflections of Ronald Dworkin's political hermeneutics, especially in his works dealing with the integrity of law. It is concluded that integrity must be seen by the legislator as a virtue of lawthat must be respected in all stages of the legislative process, because when the decision to create new rules and new rights is justified in principles of political morality, the whole conception of legislation improves in legitimacy and effectiveness.
\end{abstract}

Keywords: Integrity. Law-making. Political morality. Legitimacy.

Recebido em: 5/12/2016

Revisões requeridas em: 19/1/2017

Aceito em: 21/1/2017

\section{Sumário}

1 Introdução. 2 Legalidade e legitimidade: 0 porquê de se obedecer às leis. 30 simbolismo da lei e 0 desinteresse pela legislação. 4 A virtude da integridade e sua aplicação no âmbito do poder Legislativo. 5 Considerações finais. 6 Referências. 


\section{INTRODUÇÃO}

Após a teoria pura do Direito de Hans Kelsen, as teorias contemporâneas a respeito da decisão judicial passaram a se preocupar em resolver o problema da legitimidade das decisões, o que desencadeou o surgimento de inúmeros debates e propostas teóricas que buscaram investigar qual o melhor método para interpretar a lei e fundamentar as decisões, de uma forma que garantisse legitimidade à atuação do Judiciário e respeito ao ordenamento jurídico.

Entre elas, destaca-se a teoria do Direito como integridade, proposta por Ronald Dworkin. Por meio do romance em cadeia, Dworkin afirma ser possível uma única resposta correta no Direito para casos difíceis ao se fundamentar as decisões em princípios de moralidade política, os quais refletem os valores políticos de uma determinada comunidade.

Os questionamentos sobre quais são as melhores decisões se intensificaram no século 19 e, desde então, muito se escreveu sobre essa problemática. Por outro lado, a despeito de existirem inúmeras obras que se preocupam com a qualidade das leis desde os pré-socráticos, ${ }^{1}$ atualmente os legisladores não demonstram interesse nem preocupação com a criação de boas leis. Os poderes Executivo e Legislativo não têm observado parâmetros de qualidade para a elaboração de leis ou para a aprovação de projetos, dando margem ao nascimento de leis deficientes, sem clareza, incoerentes com a prática jurídico-política da comunidade, além da aprovação de leis que têm como pano de fundo interesses particulares e estratégicos de determinados grupos.

${ }^{1}$ Como em Platão (A República), em Aristóteles (Ética a Nicômaco), em Rousseau (O Contrato Social e Discurso Sobre as Origens e os Fundamentos da Desigualdade entre os Homens). 
Neste cenário, um dos problemas mais patentes e que será objeto desta pesquisa é a insuficiência de procedimentos que pretendem garantir um devido debate sobre o conteúdo dos projetos de lei antes da sua votação. Nem mesmo as normas que tentaram estabelecer esse debate, como é o caso do decreto $\mathrm{n}^{\mathrm{O}} 4.176 / 02$, são eficazes, por razões que serão analisadas no decorrer do texto.

A inobservância de procedimentos e a rapidez com que - muitas das vezes - são aprovados os projetos de lei, suprimem um debate que é essencial para a garantia dos interesses da comunidade. Além do mais, como o Estado de Direito visa a alcançar o bem-estar contínuo dos cidadãos por meio da legislação, são necessários certos limites à atuação do Legislativo, afastando a livre conformação e aproximando-se de um parâmetro que reflita de maneira eficaz o interesse do povo, dando maior dignidade ${ }^{2}$ à legislação.

Lênio Streck reafirma essa necessidade de limites à liberdade de conformação do legislador com o argumento de que a Constituição do Brasil de 1988 possui texto compromissório e, ainda hoje, dirigente. Essa situação fática possibilita ao povo exigir do Legislativo uma prestação de contas, no sentido de levar a sério a nossa Constituição.

não são somente os preceitos e princípios que servem como parametricidade, mas, também, esse compromisso institucional de o legislador dever "contas" à sociedade (interesse público, portanto) nas suas atribuições de elaborar atos normativos lato sensu. Essa accountability paramétrico-constitucional é representada também - e esse é um aspecto relevante na nova composição de forças nas relações de poderes nas democracias contemporâneas - pela obrigação de o poder

2 O conceito de dignidade abordado neste artigo foi concebido por Jeremy Waldronem obra intitulada $A$ dignidade da legislação. O autor fala sobre como a legislação tem sido malvista pelos cidadãos e explicita os motivos desse descrédito. Nesse contexto, o conceito de dignidade tem o propósito de conferir à legislação o devido respeito, sendo usado para se referir à qualidade do que é grande, nobre e elevado. 
Legislativo dizer quais as razões pelas quais elaborou, derrogou ou alterou determinada lei. Ou porque se omite em regulamentar determinado tema constitucional (STRECK, 2013).

A partir dessas ideias, a questão central desta pesquisa está em analisar as deficiências do processo legislativo levando à discussão em torno de uma maneira de apresentar a legislação como algo dignificado, por meio da instituição e reconhecimento da integridade como uma virtude do Direito, que orientará os legisladores na produção das leis e na justificação da criação e alteração de direitos.

Nesse sentido, objetiva-se: 1) analisar os conceitos de legalidade e legitimidade; 2) identificar os obstáculos que impedem a eficácia das leis, bem como a necessidade de uma teoria da legislação e, por fim, 3) analisar a possibilidade de apresentar o princípio da integridade de Dworkin como um parâmetro de orientação da atuação dos legisladores.

Por meio do estabelecimento de uma relação entre as exigências normativas do princípio da integridade e a prática legislativa brasileira, esta investigação oportuniza a abertura de uma reflexão que ultrapassa a questão da coerência e consistência na área da decisão jurídica, para alcançar também uma possível normatividade no campo da produção legislativa. Nessa perspectiva exploratória esta reflexão permite uma discussão sobre o próprio equilíbrio ou mediação da tensão entre constitucionalismo e democracia no âmbito da produção legislativa do Direito. Para serem alcançados esses resultados será feita uma abordagem analítica, utilizando-se das reflexões teóricas da hermenêutica política de Ronald Dworkin, especialmente em suas obras que tratam da integridade do Direito.

\section{LEGALIDADE E LEGITIMIDADE: O PORQUÊ DE SE OBEDECER ÀS LEIS}

A lei é um instrumento essencial do Direito, enquanto que a sua produção pode ser considerada a principal função do Estado. Nesse sentido, John Robert Seeley já aludiu ao "Estado de legislação" referindo-se 
ao Estado comprometido na garantia do bem-estar da sua comunidade por meio da criação contínua de leis. Em outras palavras, o Estado de legislação busca melhorar a vida dos cidadãos utilizando-se primordialmente da função típica do poder Legislativo (WALDRON, 2003).

A sociedade contemporânea, no entanto, plural e complexa, aumentou a necessidade de intervenção do Estado fazendo com que o poder Executivo passasse a legislar cada vez mais, tendo, consequentemente, responsabilidade na qualidade das leis. Quando, porém, o poder Executivo incorpora as funções do Legislativo- governando por meio de medidas provisórias com "força de lei” - surge um novo paradigma de governo: o Estado de Exceção, considerado um patamar de indeterminação entre democracia e absolutismo (AGAMBEN, 2004). Corroborando com esse entendimento, Annie Dymetman afirma:

Quando do decisionismo monista de Schmitt, o parlamento era acusado de não chegar ao consenso, de empurrar as decisões com a barriga, de servir como mera confirmação automática de decisões tomadas a portas fechadas, por conta da corrupção e da ineficácia dos parlamentares, destruindo assim a integridade e a união nacional. Como resposta a este hamletismo político e às dificuldades de governabilidade, na visão e nos tempos schmittianos, o poder Executivo passava a exercer a função primordial do Legislativo, governando através do Estado de Exceção, enquanto nos tempos da ditadura militar brasileira, através dos decretos-lei e, na nossa atual democracia, através das polêmicas medidas provisórias (2014).

Ainda, a maioria das leis que são promulgadas no Brasil teve origem em projetos de lei apresentados pelo poder Executivo ao Congresso Nacional, o que faz do Legislativo uma instância de legitimação de decisões previamente adotadas (HOMMERDING,2012). Além das políticas de bem-estar, a preocupação do governo em responder aos anseios da sociedade por meio da criação de leis também é fator de grande influência para essa inflação legislativa que vivenciamos. O que é paradoxal, no entanto, é que, 
a despeito da essencialidade da lei para a regulação da sociedade e para a consecução de políticas públicas do Estado, essa mesma lei tem recebido descrédito da comunidade.

O motivo desse descrédito é a percepção de ineficácia das leis, problema que tem relação direta com as formas pelas quais elas são criadas. Nesse cenário, antes de adentrarmos na discussão acerca da atuação do Legislativo e do Executivo, é elementar uma distinção entre legalidade e legitimidade.

A legalidade - entendida como pressuposto do governo das leis em contraposição ao governo dos homens - possui um caráter de justiça, uma vez que afasta o arbítrio do governante. De acordo com José Joaquim Gomes Canotilho, “o princípio básico do Estado de Direito é o da eliminação do arbítrio no exercício dos poderes públicos com a consequente garantia de direitos dos indivíduos perante esses poderes” (1999).

Além da previsibilidade/segurança, o princípio da legalidade também denota um segundo valor, qual seja, o da igualdade formal. Este “evita favorecimento e perseguições de caráter pessoal, pois as leis estariam escoradas em prescrições gerais e abstratas” (FERREIRA,2015).

A legitimidade, no âmbito do Direito Privado Romano, era entendida como sinônimo de legalidade, pois é uma palavra que deriva do latim legitimus (de lex) e significa aquilo que é conforme a lei (DINIZ, 2006). Esse conceito, no entanto, evoluiu e, no âmbito da linguagem política, a legitimidade é o adjetivo do Estado que consegue administrar sem a necessidade do uso constante da força, pois os membros da comunidade aceitam a autoridade vigente. Em outras palavras, a legitimidade é fruto de um consenso, por parte de toda a comunidade, sobre a própria função do Estado. 
Embora tenha grande valor, a legitimidade de um poder ou instituição pode ser questionada quando se percebe que esse consenso da comunidade foi manipulado, e isso não é característica apenas dos regimes totalitários, mas ocorre também nos regimes democráticos. O consenso pode advir de uma opressão empreendida pelos governantes; quanto maior essa opressão, menos legítimo será o Estado.

A legitimidade do Estado é uma situação que nunca se realizou efetivamente na história, a não ser como aspiração, e que, portanto, um Estado será mais ou menos legítimo conforme nele se realize o valor de consentimento manifestado livremente, por parte de uma comunidade de homens autônomos e conscientes; isto é: na medida em que se aproxima da idéia-limite da eliminação do poder e da ideologia das relações sociais (LEVI, 1984, p. 84).

Para além deste argumento, Dworkin também questiona a legitimidade de um Estado que, no momento de criação das leis, não considera a igualdade dos cidadãos. Isso porque a distribuição de riquezas é determinada pelas leis promulgadas em um país; as leis que regulamentam a previdência, assim como as leis fiscais, são exemplos de leis que influenciam diretamente a riqueza de um cidadão. Dessa forma, Dworkin chega à conclusão de que "a consideração igualitária é a virtude soberana da comunidade política”, pois a ausência dela reflete a desigualdade de um país (2005).

A busca pela legitimidade do Estado, portanto, é essencial para a sociedade contemporânea, pois é a única justificativa do porquê de se obedecer às leis, do porquê de se submeter ao domínio do homem sobre o homem. É nesse cenário, então, que se torna relevante questionarmos a atuação do poder Legislativo na criação de atos normativos, indo além do argumento da democracia - de que a legitimidade decorre do fato de que decisões políticas devem ser tomadas por pessoas eleitas pela comunidade - e buscando analisar outros obstáculos que impedem a eficácia das leis. 


\section{O SIMBOLISMO DA LEI \\ E O DESINTERESSE PELA LEGISLAÇÃO}

Segundo Ronald Dworkin, a Constituição funde questões jurídicas e morais, fazendo com que a validade de uma lei dependa da resposta a problemas morais complexos, como o problema de saber se uma determinada lei respeita a igualdade inerente a todos os homens (2007).

A crescente multiplicação do número de normas legais, no entanto, traz consigo a perda de qualidade das leis, as quais não conseguem responder aos complexos problemas da sociedade contemporânea. Desse modo, assim que uma lei é criada, ela já carrega em si uma debilidade que a torna incapaz de operar os efeitos sociais pretendidos pelo legislador ou pelo chefe do Executivo.

Essa situação de debilidade da lei tornou-se tão corriqueira que, muitas vezes, o legislador cria leis que ele mesmo sabe que não serão eficazes. A lei, nesse caso, foi criada para atendera algum clamor popular, foi usada como uma forma de o poder Executivo ou Legislativos e isentar da responsabilidade sobre determinado problema social.

E assim surge a chamada legislação simbólica. Para Luño,

la legislación simbólica posee un significado encubridor y manipulador. Quienes la elaboran producen una realidad ficticia y una falsa conciencia sobre la idoneidad de los medios jurídicos para salvaguardar la seguridad ciudadana. Pero, también son víctimas de un "autoengaño" porque los políticos y los legisladores que crean ese tipo de legislación, acaban por creerse la virtualidad de unas respuestas normativas que son puramente simbólicas (2011, p. 117).

Essa passagem evidencia o que já foi tratado anteriormente, no sentido de que há manipulação do consenso da comunidade nos regimes democráticos, pois ao prover a sensação de segurança, o Estado consegue manter a aceitação da comunidade, administrando com uma aparência de 
legitimidade. Segundo Adalberto Narciso Hommerding, a legislação penal é o melhor exemplo de legislação simbólica no Brasil e, portanto, um prato cheio para quem quer criticar os problemas decorrentes da hipertrofia legislativa e da ineficácia das leis (HOMMERDING, 2012).

Nessa ordem de ideias, um bom exemplo é a situação paradoxal do crescimento da criminalização de condutas - com o objetivo de atender à opinião pública - e, de outro lado, o crescimento de formas de despenalização dessas mesmas condutas.

Essas leis são reflexos de um momento pré-legislativo problemático, que não digeriu em tempo adequado os impulsos legislativos-estes considerados como o conjunto de razões, sujeitos que influenciam e fatores que movem o corpo legislativo a exercer sua iniciativa normativa dando azo à elaboração precipitada de leis, à criação de leis impensadas.

Assim, o momento pré-legislativo acaba sendo conduzido por grupos de pressão, os quais, no fim, são os grandes autores do Direito Penal, submetendo o debate a uma visão superficial e distorcida dos problemas sociais ao apelar para os medos e anseios da sociedade (HOMMERDING, 2012).

Consequentemente, a sociedade, quando percebe o simbolismo da lei, busca a efetividade de seus direitos no âmbito do poder Judiciário, o qual passou então a ser o protagonista na produção do Direito. O que tem feito, porém, o legislador para tentar melhorar essa situação? O que há hoje referente a uma regulação do processo legislativo?

Além do artigo 59 da Constituição Federal (que apenas lista as espécies normativas), temos a Lei Complementar n⿳⺈ 95/1998 e o Decreto $n^{\circ}$ 4. 176/2002, que, de uma forma geral, estabelecem regras a respeito da organização, estrutura, formas de alteração e redação dos atos normativos. 
O Decreto $\mathrm{n}^{\circ} 4.176 / 2002$ merece especial atenção, pois traz em seus anexos um check list - instrumento de avaliação de impacto muito analítico e criterioso - ao qual deve se ater o legislador no momento de produção das leis.

Esse check list é extenso e estabelece importantes questões que devem ser analisadas na elaboração de atos normativos no âmbito do poder Executivo, forçando uma reflexão acerca do problema e da viabilidade da lei. A título de exemplo, o decreto questiona: "Deve ser tomada alguma providência?”; “Quais as razões que determinam a iniciativa?”; "Qual é o conjunto de destinatários alcançados pelo problema, e qual o número de casos a resolver?”.

A concretização das disposições desse decreto da maneira como foi proposto exige algumas providências, como o envolvimento de sociólogos e de especialistas no debate acerca das propostas e da viabilidade da lei que se pretende elaborar, no entanto o que se percebe é uma ausência de interesse por parte dos legisladores na observância das diretrizes propostas pelo decreto.

O motivo da falta de interesse é óbvio, uma vez que a sua aplicação demandaria grande esforço, além de afastar a possibilidade de criação de leis parciais (ideologicamente comprometidas). Dito de outra forma, as leis pensadas para beneficiar grupos determinados certamente não passariam pelo filtro do decreto e, portanto, não haveria justificativa para sua produção.

Nesse sentido, Fabiana de Menezes Soares, estudiosa da legística, ${ }^{3}$ afirma que o texto da Lei Complementar 95/1998 contradiz os seus próprios fins e que

${ }^{3}$ Legística é a "ciência que atua, sob o ponto de vista material, em prol do reforço da facticidade e efetivação da legislação, bem como, sob o ponto de vista formal, otimizando a inteligibilidade e acessibilidade dos textos legais" (SOARES, 2007). 
o elaborado decreto $\mathrm{n}^{\mathrm{0}} 4.176 / 02$ prevê um instrumento para avaliação de impacto dos atos normativos, que vem sendo ignorado pelo Executivo, contraditoriamente pródigo na sua atividade legislativa que aumenta o cipoal normativo no qual estamos todos imersos (SOARES, 2007).

Isso posto, podemos concluir que há muitos obstáculos que impedem a efetividade das leis; há problemas vinculados à inflação legislativa, que faz com que seja impossível a todos os cidadãos, incluindo os juristas, terem conhecimento de todas as leis; há problemas que se originam no desinteresse dos legisladores pela criação de boas leis e há problemas relacionados à falta de um parâmetro eficaz para avaliar a qualidade das leis.

No Brasil, além do fato de as poucas normas que regulam o processo legislativo não serem observadas, devemos atentar para o fato de que se vê pouco interesse na elaboração de uma teoria capaz de dar dignidade à legislação.

Por algum motivo, todo o esforço intelectual é aplicado no âmbito do poder Judiciário, enquanto que o Legislativo é malvisto. Jeremy Waldron, em livro intitulado $A$ dignidade da legislação, faz uma afirmação que reflete, não a sua opinião, mas o nosso sentimento de desconforto com a legislação. Segundo este autor:

A legislação não é apenas deliberada, administrativa ou política: é, acima de tudo, no mundo moderno, o produto de uma assembléia - os muitos, a multidão, o populacho (ou seus representantes). Os juízes erguem-se acima de nós no seu solitário esplendor, com seus livros, seu saber e seu isolamento das condições da vida comum. Se não estão sozinhos na banca, estão rodeados por um número bem pequeno de íntimos de distinção similar, com os quais podem cultivar relações de espírito acadêmico, erudição e virtude exclusiva. Um parlamento, em contraste, é um corpo rebelde, muitas vezes maior que esse número talvez até centenas de vezes maior. Fazendo eco a Blackstone, exige-se um 
longo percurso de treinamento para que alguém se torne juiz, mas todo membro do populacho enviado pelos eleitores a Westminster pensa em si como um legislador nato. E há tantos deles que não conseguimos nos ouvir pensar. Como isso pode ser uma maneira dignificada de fazer ou modificar o Direito? (WALDRON, 2003).

A despeito dessas considerações, Waldron conclui o primeiro capítulo de seu livro no sentido de que deve haver algo em favor da legislatura, apresentando o argumento de Maquiavel, que500 anos atrás havia afirmado que boas leis podem surgir dos tumultos que muitos maldizem inconsideradamente (WALDRON, 2003).

Seguindo essa ideia, é importante passarmos a nos preocupar mais com uma teoria da legislação ou mesmo com formas e parâmetros que possam ser efetivamente aplicados no momento de produção das leis, dando-lhes legitimidade e força normativa. Com efeito, analisa-se no próximo tópico como a integridade do Direito pode contribuir, de maneira reconhecidamente modesta, para a dignificação da legislação.

\section{A VIRTUDE DA INTEGRIDADE E SUA APLICAÇÃO NO ÂMBITO DO PODER LEGISLATIVO}

O pensamento de Dworkin faz críticas ao positivismo jurídico e apresenta o Direito como uma atitude interpretativa. Seus argumentos possuem uma perspectiva hermenêutica, ou seja, analisam o Direito do ponto de vista de quem o interpreta, apresentando conceitos que são característicos de sua teoria- como os de moralidade política, juiz Hércules, integridade e romance em cadeia - os quais buscam contribuir para uma prática de interpretação e justificação das decisões judiciais que permita descobrir os direitos autênticos das pessoas, podendo se falar até mesmo em uma única resposta correta. 
O Direito, no entanto, como integridade - apresentado como um meio-termo entre as concepções convencionalista, da tradição de Hart (1997), e a pragmática, idealizada por Richard Posner (2010) e seus seguidores- possui uma sensibilidade que vai além das decisões judiciais, pois uma comunidade que aceita a integridade possui uma melhor justificação para o Direito como forma de imposição do poder do Estado. Partindo dessa ideia, é importante a menção de que a pretensão dessa pesquisa é de analisar a integridade e suas exigências apenas sob uma perspectiva que possa ser proveitosa para a legislação.

De acordo com várias vertentes da teoria política, a justificação do Estado encontra-se nos ideais de equidade, justiça e devido processo legal. Além desses ideais, Dworkin apresenta a integridade como uma quarta virtude, ${ }^{4}$ sendo esta a virtude que fará uma leitura moral do Direito e exigirá coerência nas decisões políticas, "a integridade da coerência entre as diversas concepções de moral pessoal, sob a luz de princípios de moralidade política” (SIMIONI, 2014).

Os princípios morais deverão ser levados em consideração tanto no momento de elaboração das leis quanto no momento de sua interpretação e aplicação, caso contrário a decisão política que der origem a determinada lei ou que a interpretar será incoerente com o ordenamento jurídico e, portanto, ilegítima (por não refletir os valores da comunidade). A partir desse pressuposto, é possível compreender a ideia de leitura moral da Constituição e sua importância para a democracia. ${ }^{5}$

\footnotetext{
${ }^{4}$ Sobre o porquê do termo virtude: "Essa exigência particular de moralidade política não se encontra, de fato, bem descrita no clichê de que devemos tratar os casos semelhantes de modo semelhante. Dou-lhe um título mais grandioso: é a virtude da integridade política (it is the virtue of political integrity)" (DWORKIN, 1986, p.165-166).

${ }^{5}$ A leitura moral exige que interpretemos os dispositivos abstratos da Constituição considerando que eles fazem referência a princípios morais de decência e justiça. Pressupõe que o dispositivo a ser interpretado é o reflexo de um princípio moral abstrato e que diante de
} 
Dessa forma, é notória a importância da moral da comunidade para o Direito, a qual, segundo Dworkin, se desdobra em moral pessoal e moral política (1999). A moral pessoal é o parâmetro pelo qual nós avaliamos as condutas das pessoas com quem convivemos, no sentido de serem elas coerentes ou não com as nossas próprias convicções morais. Em outras palavras, a moral pessoal exige daqueles que nos são próximos atitudes coerentes, caso contrário nosso sentimento será de frustração.

Essa expectativa de atitudes moralmente coerentes transfere-se para o Estado e para a comunidade quando falamos da moral política. A moralidade política reflete uma unidade de princípios aceitos pela comunidade, ainda que se reconheça que os cidadãos, individualmente considerados, tiveram que abrir mão de uma ou outra convicção de moral pessoal. É o conjunto coerente das convicções morais mais importantes da comunidade. A exigência de moralidade política é exatamente a virtude da integridade.

A integridade, portanto, estabelece uma união entre a vida moral e política dos cidadãos. No âmbito do Legislativo, considerar o Direito em sua integridade exige do legislador a tentativa de manter o conjunto de leis moralmente coerente (DWORKIN, 1999). A integridade não permite parcialidade, e muitas vezes não é compatível com o consenso, pois este não leva em consideração a desigualdade das pessoas e permite que direitos sejam suprimidos, que princípios sejam deixados de lado, sob o argumento de que essa é a vontade da maioria.

É por isso que a teoria do Direito como integridade é substancialista. Ela se preocupa com o conteúdo das decisões políticas simplesmente porque questões de princípios não podem ser deixadas de lado. Ademais,

um caso controverso deve-se decidir qual a melhor compreensão desse princípio considerando o seu fundamento verdadeiro e a forma como foi incorporado na prática jurídica da comunidade (DWORKIN, 2006). 
não basta que o legislador estabeleça um direito coerente em si mesmo e aparentemente justo, pois o conjunto de atos do Estado precisa ter coerência com princípios. Assim, a integridade é escarnecida

sempre que uma comunidade estabelece e aplica direitos diferentes, cada um dos quais coerente em si mesmo, mas que não podem ser defendidos em conjunto como expressão de uma série coerente de diferentes princípios de justiça, eqüidade ou devido processo legal (DWORKIN, 1999, p. 224).

As novas leis, sob essa perspectiva, não podem se originar de decisões aleatórias e desconexas. Elas devem possibilitar que o Direito seja visto como uma unidade; devem expressar um sistema único e coerente de justiça e equidade, tratando a todos os cidadãos como iguais. Inclusive na concepção procedimentalista de Klaus Günther,

uma legislação que recria um determinado direito sem examinar a sua coerência com outros direitos, ou que persegue determinados objetivos políticos de modo a fazer acordos arbitrários que conduzem ao privilégio de uma posição jurídica, não trata a todos com igual consideração e respeito (2004).

A integridade, porém, não é apenas uma versão melhorada do ideal de equidade, de que os iguais devem ser tratados de maneira igual. A integridade não é apenas coerência no sentido de que uma instituição política deve repetir as decisões que tomou no passado, pois muitas vezes ela pode se afastar da linha histórica de suas decisões se isso significar ser fiel aos princípios que a comunidade entende como mais fundamentais (DWORKIN, 1999).

A integridade é bem mais abrangente do que a coerência, pois a coerência que ela exige com as decisões do passado vincula-se às razões, aos motivos que levaram uma instituição política a decidir daquela maneira no passado. Assim, se esses motivos mudaram, uma decisão incoerente 
agora não fere a integridade, desde que se mantenha a coerência com os princípios de moralidade política. A integridade não exige coerência com políticas públicas do governo (polices), mas sim com questões de princípio.

Dessa forma, as políticas públicas podem criar discriminações que não violam a integridade, como as políticas de incentivo fiscal a determinado setor industrial ou a empresas que se estabeleçam em determinada região do país, pois objetivam equilibrar a economia e garantir progresso da comunidade como um todo. O governo tem liberdade de tomar decisões estratégicas para atingir seus objetivos políticos quando ele decide sobre questões que não são questões de princípio, porém quando ele decide sobre questões de princípio como a de permitir ou não o aborto, ele não tem liberdade de justificação, a escolha deve refletir os princípios de moralidade política daquela comunidade, portanto "uma política pública viola a integridade se ela não encontra nenhuma justificativa em princípios de moralidade política” (SIMIONI, 2014, p. 398).

Podemos perceber que a observância da integridade exige da comunidade, dos legisladores, dos juízes e dos governantes atitudes não egoístas; exige que todos sejam fiéis ao conjunto de princípios de moralidade política que rege a comunidade, ainda que isso signifique prejuízo. Nesse sentido, Dworkin descreve um modelo de comunidade baseada em princípios que seria compatível com a integridade. Para essa comunidade,

os atos políticos de todos exprimem sempre, ao se mostrar como devem ser as regras e de que modo se devem aplicá-las, um profundo e constante compromisso que exige sacrifício, não apenas por parte dos perdedores, mas também dos poderosos que teriam a ganhar com o tipo de conluio e soluções conciliatórias que a integridade proíbe (1999, p. 257).

A busca pela legitimidade política é satisfeita na fraternidade, ela faz com que os membros da comunidade cumpram com suas obrigações não apenas por imposição, por poder, mas por interesse e consideração 
pelas obrigações comunitárias. Por isso as leis não podem ser incoerentes com os princípios de moralidade política; e o princípio da integridade na legislação orientará os legisladores no melhor caminho para criação e alteração de leis.

\section{CONSIDERAÇÕES FINAIS}

A proliferação das leis, juntamente com a desconfiança da comunidade em relação aos legisladores, tem ocasionado o descrédito na legislação. A ineficácia das leis, o simbolismo e as ideologias que elas carregam abrem a possibilidade para questionarmos a legitimidade da atuação do poder Legislativo.

Como vimos, a legitimidade de uma instituição é perdida quando percebemos que o consenso da comunidade a respeito da função da própria instituição está sendo manipulado. A legislação simbólica é prova dessa manipulação, pois é uma resposta fictícia a problemas sociais de uma forma que mostra levar em consideração os anseios da comunidade, mas que na prática não possui qualquer eficácia. Assim, ao prover essa sensação de segurança, a aceitação quanto à função do poder Legislativo é mantida, o qual continua atuando com uma aparência de legitimidade.

Além disso, existem outros problemas apresentados pela legislação, como a falta de clareza, o desinteresse dos legisladores pela criação de boas leis e a inexistência de um parâmetro de avaliação, todos eles contribuindo para a ineficácia das leis. Nesse contexto, o Direito como integridade pode ser de grande utilidade para uma reconstrução do modo como vemos a legislação, orientando a produção das leis e servindo como parâmetro de análise da qualidade e coerência delas com o ordenamento jurídico. 
A integridade faz uma leitura moral do Direito e exige que as decisões sejam baseadas em um conjunto de princípios de moralidade política que refletem os ideais da comunidade. Para nós, a Constituição tem cumprido o papel de dar força normativa a convicções morais que os membros da comunidade consideram mais fundamentais. Os legisladores, portanto, não possuem liberdade de conformação na criação de leis; eles estão vinculados à Constituição simplesmente por uma questão de respeito para com os cidadãos.

Para além dessa vinculação, a integridade deve ser vista como uma virtude do Direito a ser respeitada pelo legislador em todas as etapas do processo legislativo, pois quando a decisão de criar novas normas e novos direitos for justificada em princípios de moralidade política, a legislação como um todo ganhará em legitimidade e eficácia.

\section{REFERÊNCIAS}

AGAMBEN, Giorgio. Estado de exceção. Trad. Iraci D. Poleti. 2. ed. São Paulo: Boitempo, 2004.

CANOTILHO, José Joaquim Gomes. Estado de Direito. Portugal: Gradiva, 1999.

DINIZ, Antonio Carlos de Almeida. Teoria da legitimidade do Direito e do Estado: uma abordagem moderna e pós-moderna. São Paulo: Landy, 2006.

DWORKIN, Ronald. A virtude soberana: a teoria e a prática da igualdade. Trad. Jussara Simões. São Paulo: Martins Fontes, 2005.

. O império do Direito. Trad. Jefferson Luiz Camargo. 2. ed. São Paulo: Martins Fontes,1999.

. Law's empire. Cambridge: Harvard University Press, 1986.

Levando os Direitos a Sério. Trad. Nelson Boeira. 2. ed. São Paulo:

Martins Fontes, 2007. 
DWORKIN, Ronald. O Direito da liberdade: a leitura moral da Constituição norte-americana. Trad. Marcelo Brandão Cipolla. São Paulo: Martins Fontes, 2006.

DYMETMAN, Annie. A nova via-sacra: STF, governabilidade e fetiche. Revista da Faculdade de Direito da Universidade São Judas Tadeu, n. 1, primeiro semestre 2014.

FERREIRA, Rafael Alem Mello. Jurisdição constitucional agressiva: o STF e a democracia deliberativa de Jürgen Habermas. Curitiba: Juruá, 2015.

GÜNTHER, Klaus. Teoria da argumentação no Direito e na moral: justificação e aplicação. Trad. Cláudio Molz. São Paulo: Landy Editora, 2004.

HART, Herbert L. A. O Conceito de Direito. Tradução de A. Ribeiro Mendes. Lisboa: Fundação Caloustre Gulbenkian, 1997.

HOMMERDING, Adalberto Narciso. Teoría de la Legislación y Derecho como Integridad. Curitiba: Juruá, 2012.

LEVI, Lúcio. Curso de introdução à ciência política. Un. IV. 2.ed. Brasília: UnB, 1984.

LUÑO, Antonio Enrique Pérez. El Desbordamiento de las Fuentes del Derecho. Madrid: La Ley-Actualidad,2011.

POSNER, Richard A. A Problemática da teoria moral e jurídica. São Paulo: Martins Fontes, 2010.

SIMIONI, Rafael Lazzarotto. Curso de hermenêutica jurídica contemporânea: do positivismo clássico ao pós-positivismo jurídico. Curitiba: Juruá,2014.

SOARES, Fabiana de Menezes. Legística e desenvolvimento: a qualidade da lei no quadro da otimização de uma melhor legislação. Revista da Faculdade de Direito da UFMG, Belo Horizonte, n.50, p.124-142, jan./jul. 2007.

STRECK, Lênio. Jurisdição constitucional e decisão jurídica. 3. ed. São Paulo: Revista dos Tribunais,2013.

WALDRON, Jeremy. A dignidade da legislação. Trad. Luis Carlos Borges. São Paulo: Martins Fontes,2003. 